\title{
BMJ Open Survival among the older adults with clinical signs of Lewy body dementia in 40 Swedish nursing homes: a 6-year follow-up study
}

Iris Zahirovic, Gustav Torisson, Carina Wattmo, Elisabet Londos

To cite: Zahirovic I, Torisson G, Wattmo $\mathrm{C}$, et al. Survival among the older adults with clinical signs of Lewy body dementia in 40 Swedish nursing homes: a 6 -year follow-up study. BMJ Open 2019;9:e028010. doi:10.1136/ bmjopen-2018-028010

Received 18 November 2018 Revised 18 March 2019 Accepted 30 April 2019

\section{Check for updates}

(C) Author(s) (or their employer(s)) 2019. Re-use permitted under CC BY-NC. No commercial re-use. See rights and permissions. Published by BMJ.

Clinical Memory Research Unit, Department of Clinical Sciences, Lund University, Lund, Sweden

Correspondence to

Mrs. Iris Zahirovic;

iris.zahirovic@med.lu.se

\section{ABSTRACT}

Objectives To investigate survival among elderly residents of Swedish nursing homes (NHs), with specific focus on those with two or more signs of Lewy body dementia (LBD).

Design Prospective observational study.

Setting NHs in Malmö, the third largest city in Sweden. Participants The study population was older adults (aged $\geq 65$ years) living in the $40 \mathrm{NHs}$ in Malmö. Clinical data were collected with a customised questionnaire assessing core clinical LBD signs. Patients were categorised based on $0-1$ or 2-4 LBD signs. The head nurse at each $\mathrm{NH}$ collected the study data: LBD questionnaires, electronic medication lists and electronic medical records from 2012 to 2013.

Main outcome measures 80 -month mortality. Results Five hundred and fifty-eight (96\%) of the residents were deceased at follow-up; among these, mean $(95 \% \mathrm{Cl})$ overall survival time was $29(28-31)$ months. Mean survival differed between the LBD groups; those with 0-1 LBD signs lived 8 months longer than those with 2-4 LBD signs. Mortality risk for residents in the LBD 2-4 group was also significantly higher. HR adjusted for age and sex was $\mathrm{HR}(95 \% \mathrm{Cl}) 1.60$ (1.30 to 1.97). Mortality risk was also significantly higher in residents with signs of fluctuating cognition 1.36 (1.15 to 1.62), rapid eye movement sleep behaviour disorder 1.49 (1.11 to 1.98), balance problems 1.36 (1.14 to 1.61$)$ or rigidity 1.41 (1.18 to 1.68 ).

Conclusions This large, longitudinal study shows the important survival effects of identifying and diagnosing older adults NH residents who have two or more LBD signs.

\section{BACKGROUND}

Dementia is one of the most common diagnoses among the older adults; it contributes to major disabilities and is followed, in many cases, by a relatively rapid onset of need for nursing care and even nursing home $(\mathrm{NH})$ admission. $^{12}$

Today, over 35 million people live with dementia-a number expected to double every 20 years. $^{3}{ }^{4}$ The majority of these patients suffer from Alzheimer's disease (AD),
Strenghts and limitations of this study

Complete coverage of all 40 nursing homes (NHs) in a relatively large geographic region.

- A strength of this study was that it investigated all $\mathrm{NHs}$ in a large Swedish city with data from $96 \%$ of the residents, including observational data, electronic medical and medication records.

- A long follow-up of 6 years is a strength of this study.

- No formal Lewy body dementia (LBD) diagnoses were made within the present study. However, data on existing LBD diagnoses were collected from the computerised medical records.

- A limitation is the cross-sectional nature of the initial data collection. In addition, the participants were at different stages of their disease and data on severity of dementia, comorbidity and function was lacking.

followed by vascular dementia and Lewy body dementia (LBD); dementia with Lewy bodies (DLB) and Parkinson disease dementia. ${ }^{5}$ These dementia diseases cause clinical symptoms that may be difficult to differentiate. ${ }^{5-7}$

Individuals with LBD have a more rapid and aggressive course of dementia, especially if they also have $\mathrm{AD}$ pathology with difficult symptomatology and core signs (according to the 2017 LBD criteria) such as visual hallucinations, parkinsonism, fluctuating cognition and rapid eye movement sleep behaviour disorder (RBD).$^{8-10}$

Furthermore, according to Muller et al some prognostic factors may be the increased prevalence and early emergence of neuropsychiatric symptoms (NPSs) in LBD patients. ${ }^{11}$

These patients' neuroleptic sensitivity is also important to consider; this condition is due to a failure to upregulate dopamine D2 receptors or reduced dopaminergic innervation after treatment with antipsychotics. ${ }^{12}$

Studies of the epidemiological prevalence of LBD are scarce, most likely because this condition presents a challenging psychological and neurological symptom profile and is 
not generally well understood among medical staff across specialities, including primary care. ${ }^{713}$ NPSs with a prevalence of $>80 \%$, such as agitation, aggression, hallucinations, depression and apathy, are common in dementia NHs. ${ }^{1415}$

Treatment of NPSs is divided into pharmacological and non-pharmacological strategies, with growing encouragement from professional organisations such as the European Medicines Agency and the Swedish National Board of Health and Welfare (NBHW), as well as opinion-leading clinical research groups, for the use of non-pharmacological treatments. ${ }^{16-21}$

Unfortunately, pharmacological treatments for NPSs consist of different antipsychotic medication, which lead to adverse reactions and events including extrapyramidal symptoms, rigidity, higher risk for cerebral vascular insults, further cognitive decline, orthostatism and shorter survival. ${ }^{22-26}$ It is of note that some of these effects are also a part of the LBD symptom profile.

However, clinicopathological studies of LBD have shown an association between visual hallucinations and a cholinergic innervation deficit explaining potential benefits of cholinesterase inhibitor treatment in LBD individuals who also suffer from visual hallucinations. ${ }^{27-30}$

The study aim were to determine the survival rates and duration among the older adults living with dementia in $\mathrm{NHs}$ in the third largest Swedish city, in relation to core LBD signs. Our hypothesis was that survival in older adults in NHs is influenced by the LBD and thereby possibly of the reported clinical signs of LBD.

\section{METHODS}

\section{Study design}

The study was designed to include all $\mathrm{NH}$ residents in Malmö, Sweden's third largest city with over 320000 inhabitants. This study is a cross-sectional study with data used according to the official registry, there were 40 dementia NHs in Malmö during the study period (20122013), all of which were included. The participants were at different stages of their diseases.

The study population was all residents aged $\geq 65$ years whose core LBD signs, electronic hospital records and electronic medication lists were available during 20122013 (figure 1). Date of death, used to analyse survival, was collected 6 years after the study was begun (January 2012-August 2018).

\section{Procedures}

The main source of clinical data was a questionnaire specifically designed to assess clinical signs of LBD. This questionnaire was compatible with the clinical consensus DLB criteria at the time and with the diagnostic form LBD diagnostic symptoms by the Lewy Body Dementia Association. ${ }^{31} 32$ We chose four main LBD signs, which are equivalent to the four core clinical criteria in the recently updated DLB consortium report. ${ }^{8}$

\section{Starting population: $\mathrm{N}=650$ residents}

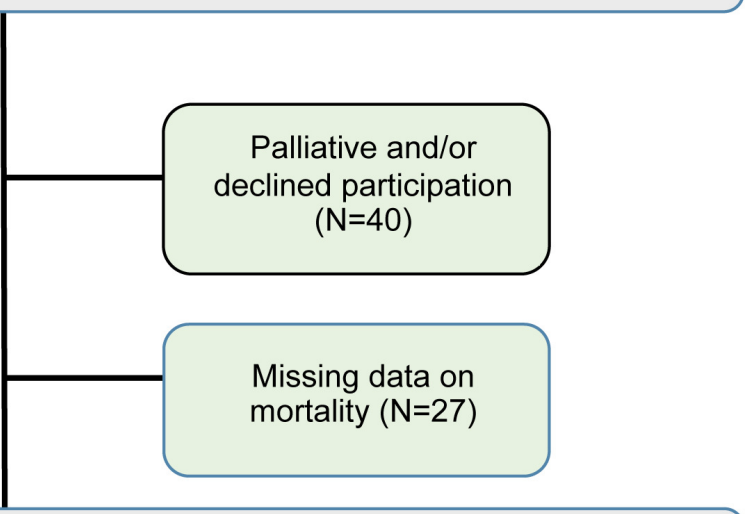

Final population: $\mathrm{N}=583$ residents

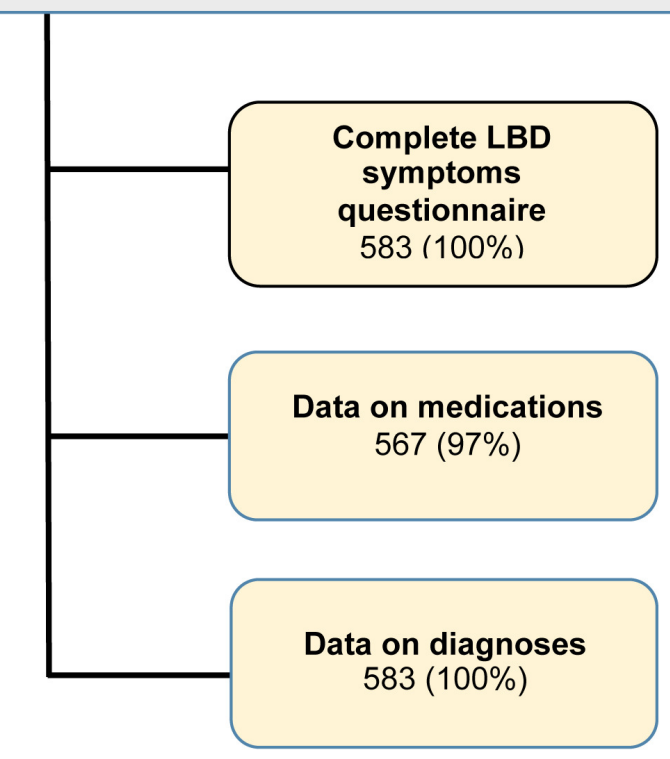

Figure 1 Flowchart of the study population from 40 nursing homes presenting the specific size of the collected data. Age: $\geq 65$ years. LDB, Lewy body dementia; N, number.

The nursing staff at each NH collected data at their institution. Swedish NH staff usually include a physician, a head nurse and several assistant nurses who care for an average of 15 residents. A seminar on the study for staff members at each $\mathrm{NH}$ was held and was led by a physician and study author (IZ). The seminar included information and instructions about scoring the presence/absence of clinical LBD signs: LBD $0-1$; zero or one core sign of LBD, LBD 2-4: two more signs of LBD (parkinsonism, visual hallucinations, fluctuating cognition and RBD). A more detailed description of the questionnaire has been previously published. ${ }^{33}$

The head nurse completed the study questionnaires and collected each resident's computerised medical record and medication list from the Swedish National Medication Dispensing System (NMDS).

Dementia diagnoses are usually made by a physician from primary care, who is also responsible for most $\mathrm{NH}$ 
residents' treatments. We must presume that the dementia diagnoses collected for this study were made according to a 'basal dementia investigation', in accordance with the Swedish NBHW. ${ }^{34}$ The basal dementia investigation consists of cognitive testing, relevant laboratory tests, CT and/or MRI (evaluated by a radiologist) and a structured anamnestic interview of the patient and/or family members by the physician.

The first diagnostic level determines whether dementia is present and at the second level, the etiological dementia diagnosis is specified. In our study, formal etiological diagnoses were found from computerised medical records in 433 (74\%); dementia None - other specified (NOS) (27\%), AD (27\%), AD-mix (22\%), vascular dementia (VaD) $(19 \%)$ and DLB/PDD (5\%).

Swedish NHs are conducted by the municipality and for a $\mathrm{NH}$ placement they require that elderly have dementia at the first or second diagnostic level.

\section{Medical data}

Collection of data from the NMDS included formal dementia diagnosis (yes/no), treatment information and deceased patients' dates of death. ${ }^{35}$ The Anatomical Therapeutic Chemical (ATC) Classification System was used to categorise medication antipsychotics (N05A) and antidementia medicines (N06D). We initially intended to analyse survival effects of medication (antidementia and antipsychotics) but decided not to due to inadequate power and the cross-sectional nature of the data collection.

\section{Patient and public involvement}

Patients were not involved in the design of the study. However, the patients were involved in the study in the sense that they gave their informed consent to participate.

\section{Statistical analysis}

For statistical analyses, we used IBM SPSS for Windows V.22.0.

$\mathrm{NH}$ residents were divided into dichotomous groups: according to number of LBD signs $(0-1 / 2-4)$. Data are presented as mean $(95 \% \mathrm{CI})$ unless otherwise noted. Kaplan-Meyer curves were constructed to show the survival distribution for all residents and log rank tests were used to compare survival between groups. Multivariate Cox regression analysis was performed to identify possible covariates of survival. In the Cox regression analysis, we controlled for age and sex. A $\mathrm{p}<0.05$ was considered statistically significant.

\section{RESULTS}

Study population characteristics are presented in table 1 . All patients had dementia at the first diagnostic level 558 $(100 \%)$ and $433(74 \%)$ had a formal dementia diagnosis (second diagnostic level) registered in the electronic data system. These were our available data. Survival data were collected 6 years after the study was initiated (January
Table 1 Demographics

\begin{tabular}{l} 
Study population \\
\hline N (\%), \\
$583(100)$
\end{tabular}

\begin{tabular}{ll}
\hline Deceased $^{\star}$ & $558(96)$ \\
Sex, female & $444(76)$ \\
\hline Age, years, $\geq 86$ & $333(57)$ \\
\hline Formal dementia diagnosis $†$ & $433(100)$ \\
\hline Dementia NOS & $115(27)$ \\
\hline Alzheimer & $115(27)$ \\
\hline Alzheimer-mix & $96(22)$ \\
\hline Vascular dementia & $85(19)$ \\
\hline DLB/PDD & $22(5)$ \\
\hline Study groups $\ddagger$ & $583(100)$ \\
\hline LBD 0-1 & $467(80)$ \\
\hline LBD 2-4 & $116(20)$ \\
\hline Clinical LBD signs§ & \\
\hline Parkinsonism & $39(7)$ \\
\hline Fluctuating cognition & $214(37)$ \\
\hline Visual hallucinations & $118(20)$ \\
\hline RBD & $52(9)$ \\
\hline Balance problems & $233(40)$ \\
\hline Rigidity & $182(31)$ \\
\hline Medicationף & $122(21)$ \\
\hline Antipsychotics & $185(33)$ \\
\hline
\end{tabular}

*All residents who were deceased after 80 months from study start. †Formal dementia diagnosis according to basal guidelines for dementia investigation from the Swedish NBHW, second level where residents had a formal etiological diagnosis 433/583 (74\%). fLBD 0-1: zero or one sign of LBD, LBD 2-4: two or more signs of LBD.

§Clinical LBD signs according to the study questionnaire. IMedication according to ATC coding: antipsychotics (ATC: N05A) and antidementia medication (ATC: N06D). Existing data on medication 567 (100\%).

ATC, Anatomical Therapeutic Chemical Classification System; LBD, Lewy body dementia; NBHW, National Board of Health and Welfare.

2012-August 2018), at which time 558 (96\%) of the residents were deceased. Among the deceased residents, mean survival time was 29 (28-31) months. In an earlier study of the same population, we reported that $20 \%$ of the residents had 2-4 LBD core signs. ${ }^{33}$

Twenty-one per cent of the residents were treated with antipsychotics and $33 \%$ with antidementia medication (table 1).

\section{Survival based on LBD group}

The mean survival time differed between the LBD groups, with residents in LBD 2-4 living 8 months shorter than those with LBD 0-1 ( $\mathrm{p}=0.0004)$. 


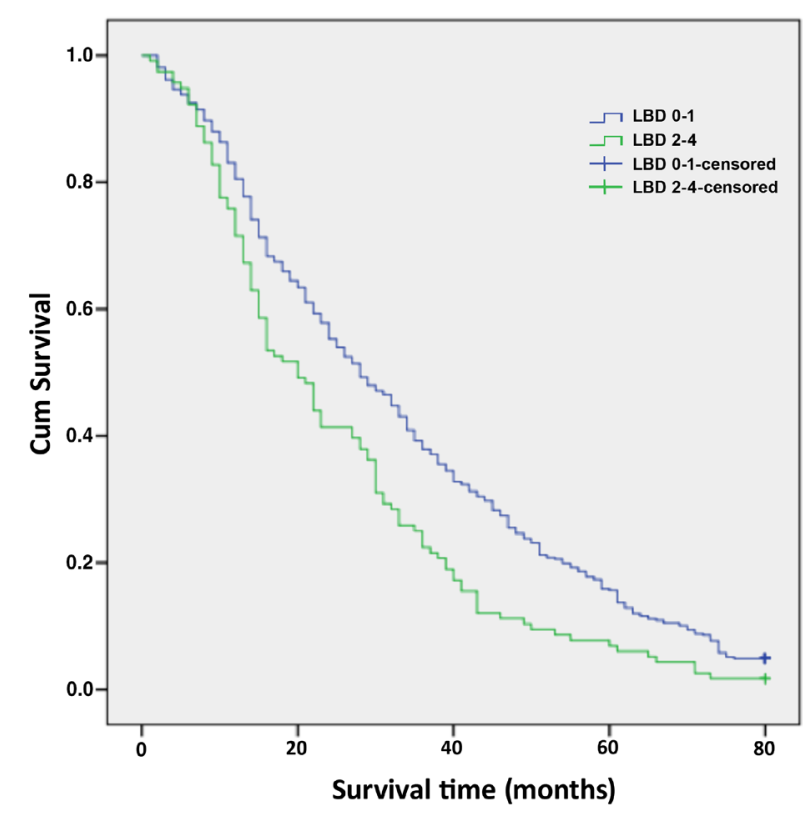

Figure 2 Kaplan-Meier survival curves comparing survival among elderly residents with LBD $0-1$ and LBD 2-4 signs. Kaplan-Meier estimates of 80-month survival time from reported time of onset for the two groups (LBD 0-1 and LBD $2-4)$. Log rank $X^{2}(d f=1, n=583)=14.8, p=0.0001$. LBD; Lewy body dementia.

Mortality risk for residents in the LBD 2-4 group was also significantly higher, as shown in the Kaplan-Meier graph in figure 2.

\section{Survival in relation to LBD signs}

Examining LBD signs from the study questionnaire, we found that mortality risk was significantly higher among residents with signs of fluctuating cognition, RBD, balance problems and stiffness (table 2).

\section{DISCUSSION}

In this $\mathrm{NH}$ population-based study, we identified that having two or more core LBD signs was associated with a significant reduction in survival time. Several studies have shown a more rapid decline, lower quality of life
(QoL) and more intensive medical and nursing care needs in LBD patients. ${ }^{36-38}$ Our residents did not have formal LBD diagnoses; rather, they were divided into groups based on their number of LBD signs, as reported by NH personnel, and thus may not be comparable to previous studies.

The NH patients in our study with 2-4 LBD signs had increased mortality risk and shorter life expectancy (table 3, figure 2). Therefore, we suggest increased number of LBD signs, as a marker of the severity of the underlying pathophysiology (alfa-synuclein, Lewy bodies and Lewy neurites).

This is in accordance with a neuropathological study by Fujishiro et $a l^{39}$ showing increased alfa-synuclein pathology with increasing number of LBD core symptoms. In this study, the core symptoms of the consensus criteria from 2005 (parkinsonism, visual hallucinations, fluctuating alertness/cognition) were used complemented with RBD, the same signs which we used in our study.

The fact that the prevalence of LBD signs was the strongest predictive factor for survival suggests that more than the formally LBD diagnosed $5 \%$ of the $\mathrm{NH}$ residents might have undiagnosed LBD.

A recent study by Savica $e t a t^{40}$ also showed shorter survival among those diagnosed with LBD, among whom death occurred 4years earlier (based on date of diagnosis), at a median age of 77 years, compared with an age-matched and sex-matched general population group.

Herein, we have found a significantly shorter mean survival time, by 8 months timed from the beginning of the study period, among patients with $2-4 \mathrm{LBD}$ signs. This finding was within a population with a high median age of 87 years, who were thus likely to be at the end stages of their lives.

We also found that the LBD signs of fluctuating cognition, RBD, balance problems and rigidity predicted a significantly shortened life expectancy (table 2). It is, however, hard to make conclusions on the survival effect of these signs without further adjustment for, for example, level of cognitive impairment or comorbidity. Jellinger $e t a l^{41}$ studied predictors of survival among DLB patients and found similar results in which fluctuating

Table 2 Mortality risk based on clinical signs

\begin{tabular}{|c|c|c|c|c|}
\hline \multirow[b]{2}{*}{$\begin{array}{l}\text { Clinical signs from the } \\
\text { questionnaire }\end{array}$} & \multicolumn{4}{|l|}{ HR $(95 \% \mathrm{Cl})$} \\
\hline & $\begin{array}{l}\text { Model } 1 \\
\text { (crude estimates) }\end{array}$ & $P$ value & $\begin{array}{l}\text { Model } 2 \\
\text { (estimates adjusted for age } \\
\text { and sex) }\end{array}$ & $P$ value \\
\hline Fluctuating cognition (no*, yes) & 1.36 (1.15 to 1.62$)$ & 0.0004 & 1.35 (1.13 to 1.60$)$ & 0.001 \\
\hline Visual hallucinations (no*, yes) & $1.10(0.90$ to 1.36$)$ & 0.330 & 1.23 (0.99 to 1.52$)$ & 0.052 \\
\hline Balance problems (no*, yes) & 1.36 (1.14 to 1.61$)$ & 0.0005 & 1.31 (1.11 to 1.56$)$ & 0.002 \\
\hline Rigidity (no*, yes) & 1.41 (1.18 to 1.68$)$ & 0.0002 & 1.45 (1.21 to 1.74$)$ & $<0.001$ \\
\hline
\end{tabular}

*Set reference value.

$\mathrm{RBD}$, rapid eye movement sleep behaviour disorder. 
Table 3 Mortality risk based on baseline variables and LBD groups

HR (95\% Cl)

\begin{tabular}{|c|c|c|c|c|}
\hline & \multicolumn{4}{|l|}{ HR $(95 \%$ CI) } \\
\hline $\begin{array}{l}\text { Sex N (\%) (male*, } \\
\text { female) }\end{array}$ & $0.94(0.78$ to 1.15$)$ & 0.560 & 0.80 (0.65 to 0.97$)$ & 0.024 \\
\hline
\end{tabular}

*Set reference value.

LBD, Lewy body dementia; LBD 0-1, zero or one sign of LBD; LBD 2-4, two or more signs of LBD.

cognition was a negative prognostic marker of shorter survival.

Several large studies have shown shorter survival times among residents with dementia treated with antipsychotics; all conclude by encouraging less use of psychotropics, which has also been a consistent message in important clinical guidelines. ${ }^{16-18} 20$

In addition, some have reported survival benefits of treatment with different antidementia medications and further studies are needed to demonstrate if this also is valid for $\mathrm{NH}$ populations. ${ }^{27} 4243$

Our analyses of different antipsychotic and antidementia treatments were not conclusive in this study population of elderly $\mathrm{NH}$ patients due to insufficient power.

However, in our previous study, we showed that increased usage of antipsychotics was associated with an increased number of LBD signs. ${ }^{33}$

\section{Strengths and limitations of this study}

We identified residents with two or more LBD signs (based on core LBD symptoms described in consensus criteria) and categorised them as at risk for inappropriate treatment due to misdiagnosis. ${ }^{8}$ A strength of this study was its large $\mathrm{N}$, with data collected by nurses who followed a consistent questionnaire protocol and a long follow-up of 6 years ( 80 months). In addition, we used medical records across all $40 \mathrm{NHs}$ with data from $96 \%$ of the residents, including observational data, electronic medical and medication records.

A limitation is the cross-sectional nature of the initial data collection. In addition, the participants were at different stages of their disease and data on severity of dementia, comorbidity and function was not possible to collect. Therefore, the Cox regression models were only adjusted for age and gender.

Although our use of a non-validated questionnaire may also be considered a limitation, over $90 \% \quad(n=13)$ of the residents with a formal LBD diagnosis, according to computerised medical records, were categorised in the 2-4 LBD group, suggesting that the instrument has face validity.

\section{CONCLUSIONS}

The main study finding is that elderly NH patients with two or more LBD signs are at significantly increased mortality risk relative to other elderly $\mathrm{NHs}$ residents and therefore are important to identify. The identification of possible LBD is beneficial for a more appropriate medical treatment and nursing care and prevention of unnecessary hospital admissions.

Contributors IZ was a major contributor in writing the manuscript, data collection, data analysis and the result interpretation. EL was responsible for study concept and design, contributed to the result interpretation, manuscript writing and the critical revision of the manuscript for important intellectual content. GT was responsible for the critical revision of the manuscript and for important intellectual content. CW data interpretation and statistical analysis. All authors read and approved the final manuscript and consented to publish this manuscript.

Funding This work was partially supported by Governmental Funding of Clinical Research within theNational Health Services (ALF), Swedish Research Council under grant number 523-2010-520.

Competing interests None declared.

Patient consent for publication Parental/Guardian consent obtained.

Ethics approval The Regional Ethical Review Board in Lund approved this study. Provenance and peer review Not commissioned; externally peer reviewed.

Data sharing statement Hereby we confirm that there is none data sharing from this unpublished study.

Open access This is an open access article distributed in accordance with the Creative Commons Attribution Non Commercial (CC BY-NC 4.0) license, which permits others to distribute, remix, adapt, build upon this work non-commercially, and license their derivative works on different terms, provided the original work is properly cited, appropriate credit is given, any changes made indicated, and the use is non-commercial. See: http://creativecommons.org/licenses/by-nc/4.0/.

\section{REFERENCES}

1. Langballe EM, Engdahl B, Nordeng H, et al. Short- and long-term mortality risk associated with the use of antipsychotics among 26,940 dementia outpatients: a population-based study. Am J Geriatr Psychiatry 2014;22:321-31.

2. Rongve A, Vossius $\mathrm{C}$, Nore $\mathrm{S}$, et al. Time until nursing home admission in people with mild dementia: comparison of dementia with Lewy bodies and Alzheimer's dementia. Int J Geriatr Psychiatry 2014;29:392-8.

3. Wimo A, Jönsson L, Bond J, et al. The worldwide economic impact of dementia 2010. Alzheimers Dement 2013;9:1-11.

4. Ferri CP, Prince M, Brayne C, et al. Global prevalence of dementia: a Delphi consensus study. Lancet 2005;366:2112-7. 
5. Hogan DB, Fiest KM, Roberts Jl, et al. The Prevalence and Incidence of Dementia with Lewy Bodies: a Systematic Review. Can J Neurol Sci 2016;43(Suppl 1):S83-S95.

6. Mollenhauer B, Förstl H, Deuschl G, et al. Lewy body and parkinsonian dementia: common, but often misdiagnosed conditions. Dtsch Arztebl Int 2010;107:684-91.

7. Aarsland D, Rongve A, Nore SP, et al. Frequency and case identification of dementia with Lewy bodies using the revised consensus criteria. Dement Geriatr Cogn Disord 2008;26:445-52.

8. McKeith IG, Boeve BF, Dickson DW, et al. Diagnosis and management of dementia with Lewy bodies: Fourth consensus report of the DLB Consortium. Neurology 2017;89:88-100.

9. McKeith I, Mintzer J, Aarsland D, et al. Dementia with Lewy bodies. Lancet Neurol 2004;3:19-28.

10. Nedelska Z, Ferman TJ, Boeve BF, et al. Pattern of brain atrophy rates in autopsy-confirmed dementia with Lewy bodies. Neurobiol Aging 2015;36:452-61.

11. Mueller $C$, Ballard $C$, Corbett $A$, et al. The prognosis of dementia with Lewy bodies. Lancet Neurol 2017;16:390-8.

12. Piggott MA, Perry EK, Marshall EF, et al. Nigrostriatal dopaminergic activities in dementia with Lewy bodies in relation to neuroleptic sensitivity: comparisons with Parkinson's disease. Biol Psychiatry 1998;44:765-74.

13. Ballard C, Grimmer T. Improving diagnosis of possible DLB: is there a role for MIBG myocardial scintigraphy? Neurology 2013;81:1730-1.

14. Selbæk G, Engedal K, Bergh S. The prevalence and course of neuropsychiatric symptoms in nursing home patients with dementia: a systematic review. J Am Med Dir Assoc 2013;14:161-9.

15. Hessler JB, Schäufele M, Hendlmeier I, et al. Behavioural and psychological symptoms in general hospital patients with dementia, distress for nursing staff and complications in care: results of the General Hospital Study. Epidemiol Psychiatr Sci 2018;27:278-87.

16. US Food and Drug Administration. Information for healthcare professionals: conventional antipsychotics [Internet]. 2008 (accessed 16 Jun 2008)

17. Szmidt M. Medical treatment in elderly with behavioural and psychological symptoms in dementia-BPSD. Swedish medical products agency 2008;5:15-24.

18. European Medicines Agency. CHMP assessment report on conventional antipsychotics.Procedure under Article 5(3) of Regulation (EC) No 726. 2004 https://www.ema.europa.eu/ documents/report/chmp-assessment-report-conventionalantipsychotics-procedure-under-article-53-regulation-ec-no-726/ 2004_en.pdf.

19. The Swedish National Board of Health and Welfare. Användning av antipsykotiska läkemedel hos äldre [The usage of antipsychotic medication according to Swedish National Board of Health and Welfare]. The Swedish National Board of Health and Welfare 2015.

20. The Swedish National Board of Health and Welfare. Indicators for good medical treatment in older persons. https://lakemedelsboken. se/kapitel/lakemedelsanvandning/lakemedelsbehandling_hos_aldre. html.

21. Gauthier S, Cummings J, Ballard C, et al. Management of behavioral problems in Alzheimer's disease. Int Psychogeriatr 2010;22:346-72.

22. Schneider LS, Dagerman K, Insel PS. Efficacy and adverse effects of atypical antipsychotics for dementia: meta-analysis of randomized, placebo-controlled trials. Am J Geriatr Psychiatry 2006;14:191-210.

23. Wang PS, Schneeweiss S, Avorn J, et al. Risk of death in elderly users of conventional vs. atypical antipsychotic medications. $N$ Engl J Med 2005;353:2335-41.

24. Ballard C, Isaacson S, Mills R, et al. Impact of Current Antipsychotic Medications on Comparative Mortality and Adverse Events in
People With Parkinson Disease Psychosis. J Am Med Dir Assoc 2015;16:898.e1-898.e7.

25. Lee PE, Sykora K, Gill SS, et al. Antipsychotic medications and drug-induced movement disorders other than parkinsonism: a population-based cohort study in older adults. J Am Geriatr Soc 2005;53:1374-9.

26. Vigen CL, Mack WJ, Keefe RS, et al. Cognitive effects of atypical antipsychotic medications in patients with Alzheimer's disease: outcomes from CATIE-AD. Am J Psychiatry 2011;168:831-9.

27. Aarsland D, Brønnick K, Karlsen K. Donepezil for dementia with Lewy bodies: a case study. Int J Geriatr Psychiatry 1999;14:69-72.

28. Aarsland D, Mosimann UP, McKeith IG. Role of cholinesterase inhibitors in Parkinson's disease and dementia with Lewy bodies. $J$ Geriatr Psychiatry Neurol 2004;17:164-71.

29. McKeith I, Del Ser T, Spano P, et al. Efficacy of rivastigmine in dementia with Lewy bodies: a randomised, double-blind, placebocontrolled international study. Lancet 2000;356:2031-6.

30. Stinton C, McKeith I, Taylor JP, et al. Pharmacological Management of Lewy Body Dementia: A Systematic Review and Meta-Analysis. Am J Psychiatry 2015;172:731-42.

31. Lewy Body Dementia Association. Lewy body dementia diagnostic symptoms. https://www.lbda.org/go/symptoms-0.

32. McKeith IG, Dickson DW, Lowe J, et al. Diagnosis and management of dementia with Lewy bodies: third report of the DLB Consortium. Neurology 2005;65:1863-72.

33. Zahirovic I, Wattmo C, Torisson G, et al. Prevalence of Dementia With Lewy Body Symptoms: A Cross-Sectional Study in 40 Swedish Nursing Homes. J Am Med Dir Assoc 2016;17:706-11.

34. The Swedish National Board of Health and Welfare. National guidelines for health and social care. 2010.

35. Zahirovic I, Torisson G, Wattmo C, et al. Psychotropic and antidementia treatment in elderly persons with clinical signs of dementia with Lewy bodies: a cross-sectional study in 40 nursing homes in Sweden. BMC Geriatr 2018;18:50.

36. Boström F, Jönsson L, Minthon L, et al. Patients with dementia with lewy bodies have more impaired quality of life than patients with Alzheimer disease. Alzheimer Dis Assoc Disord 2007;21:150-4.

37. Stubendorff K, Hansson O, Minthon L, et al. Differences in survival between patients with dementia with Lewy bodies and patients with Alzheimer's disease--measured from a fixed cognitive level. Dement Geriatr Cogn Disord 2011;32:408-16.

38. Schneider JA, Arvanitakis Z, Yu L, et al. Cognitive impairment, decline and fluctuations in older community-dwelling subjects with Lewy bodies. Brain 2012;135:3005-14.

39. Fujishiro H, Ferman TJ, Boeve BF, et al. Validation of the neuropathologic criteria of the third consortium for dementia with Lewy bodies for prospectively diagnosed cases. J Neuropathol Exp Neurol 2008;67:649-56.

40. Savica R, Grossardt BR, Bower JH, et al. Survival and Causes of Death Among People With Clinically Diagnosed Synucleinopathies With Parkinsonism: A Population-Based Study. JAMA Neurol 2017;74:839-46.

41. Jellinger KA, Wenning GK, Seppi K. Predictors of survival in dementia with lewy bodies and Parkinson dementia. Neurodegener Dis 2007;4:428-30.

42. Aarsland D, Ballard C, Walker Z, et al. Memantine in patients with Parkinson's disease dementia or dementia with Lewy bodies: a double-blind, placebo-controlled, multicentre trial. Lancet Neurol 2009;8:613-8.

43. Emre M, Tsolaki M, Bonuccelli U, et al. Memantine for patients with Parkinson's disease dementia or dementia with Lewy bodies: a randomised, double-blind, placebo-controlled trial. Lancet Neurol 2010;9:969-77. 